\title{
Article
}

\section{Exploiting the Potential of Supported Magnetic Nanomaterials as Fenton-Like Catalysts for Environmental Applications}

\author{
Jorge González-Rodríguez ${ }^{1, * \mathbb{C}}$, María Gamallo ${ }^{1}$, Julio J. Conde ${ }^{1} \mathbb{D}$, Zulema Vargas-Osorio ${ }^{2,3}{ }^{(0}$, \\ Carlos Vázquez-Vázquez ${ }^{2}$,, , Yolanda Piñeiro ${ }^{2}$, José Rivas ${ }^{2}\left(\mathbb{D}\right.$, Gumersindo Feijoo ${ }^{1(1)}$ \\ and Maria Teresa Moreira ${ }^{1}$ (D)
}

1 CRETUS Department of Chemical Engineering, Universidade de Santiago de Compostela, 15782 Santiago de Compostela, Spain; maria.gamallo.miron@gmail.com (M.G.); julio.conde@usc.es (J.J.C.); gumersindo.feijoo@usc.es (G.F.); maite.moreira@usc.es (M.T.M.)

2 Laboratory of Magnetism and Nanotechnology, Departments of Physical Chemistry, Faculty of Chemistry, and Applied Physics, Faculty of Physics, Universidade de Santiago de Compostela, 15782 Santiago de Compostela, Spain; zulema.vargas@tnuni.sk (Z.V.-O.); carlos.vazquez.vazquez@usc.es (C.V.-V.); y.pineiro.redondo@usc.es (Y.P.); jose.rivas@usc.es (J.R.)

3 Centre for Functional and Surface Functionalized Glass, Alexander Dubček University of Trenčín, Študentská 2, 91150 Trenčín, Slovakia

* Correspondence: jorgegonzalez.rodriguez@usc.es; Tel.: +34-8818-16771

\section{check for}

updates

Citation: González-Rodríguez, J.; Gamallo, M.; Conde, J.J.; VargasOsorio, Z.; Vázquez-Vázquez, C.; Piñeiro, Y.; Rivas, J.; Feijoo, G.; Moreira, M.T. Exploiting the Potential of Supported Magnetic Nanomaterials as Fenton-Like Catalysts for Environmental Applications. Nanomaterials 2021, 11, 2902. https:// doi.org/10.3390/nano11112902

Academic Editor: Lyudmila M. Bronstein

Received: 7 October 2021

Accepted: 27 October 2021

Published: 29 October 2021

Publisher's Note: MDPI stays neutral with regard to jurisdictional claims in published maps and institutional affiliations.

\begin{abstract}
In recent years, the application of magnetic nanoparticles as alternative catalysts to conventional Fenton processes has been investigated for the removal of emerging pollutants in wastewater. While this type of catalyst reduces the release of iron hydroxides with the treated effluent, it also presents certain disadvantages, such as slower reaction kinetics associated with the availability of iron and mass transfer limitations. To overcome these drawbacks, the functionalization of the nanocatalyst surface through the addition of coatings such as polyacrylic acid (PAA) and their immobilization on a mesoporous silica matrix (SBA15) can be factors that improve the dispersion and stability of the nanoparticles. Under these premises, the performance of the nanoparticle coating and nanoparticle-mesoporous matrix binomials in the degradation of dyes as examples of recalcitrant compounds were evaluated. Based on the outcomes of dye degradation by the different functionalized nanocatalysts and nanocomposites, the nanoparticles embedded in a mesoporous matrix were applied for the removal of estrogens (E1, E2, EE2), accomplishing high removal percentages (above $90 \%$ ) after the optimization of the operational variables. With the feasibility of their recovery in mind, the nanostructured materials represented a significant advantage as their magnetic character allows their separation for reuse in different successive sequential batch cycles.
\end{abstract}

Keywords: Fenton; nanoparticle; kinetic; SBA-15; estrogen; reuse; magnetic catalyst

\section{Introduction}

Advanced oxidation processes (AOPs) are based on the formation of reactive oxygen species (ROS) that lead to the non-specific oxidation of pollutants present in wastewater. These non-selective species possess a high oxidation potential with the ability of removing a wide variety of organic molecules, such as pharmaceutically active compounds (PhACs), endocrine disruptors (EDCs) and personal care products (PPCPs), identified as a potential threat to wildlife and humans when released into the environment [1,2]. Although these types of contaminants are usually detected in wastewater effluents in the range of parts per billion, adverse effects on receiving ecosystems have been demonstrated even at low concentrations [3,4]. In this sense, ROS species induce structural changes in their chemical structures, leading to their decomposition and reducing the risks associated with the presence of reaction intermediates in the effluent [5].

AOPs include a wide range of different approaches, such as ozone-based processes [6], semiconductor-based photocatalysis [7], Fenton-type reactions [8], or hybrid processes 
such as photo-Fenton or the peroxone process [9]. Compared to other options, the Fenton catalysis process has several noteworthy advantages, such as high oxidative capacity, low cost of chemicals and operational simplicity. However, several drawbacks have been mentioned that may limit its application: low efficiency at neutral $\mathrm{pH}$ and the generation of large quantities of iron sludge when using homogeneous catalysts, which must be managed before the discharge of the final effluent $[8,10]$. In order to address these limitations, a heterogeneous catalysis approach based on magnetite nanoparticles is proposed, as their superparamagnetic properties allow their simple recovery by means of a magnetic field. Although the environmental implications in the synthesis of this type of nanomaterials must be considered [11], the possibility of their reuse could limit the potential associated impacts. Based on the premise of a nanocatalyst with iron on its surface and magnetic potential, a separation unit must be implemented to allow its use in subsequent reaction cycles, without significant loss of catalytic activity [12-14].

Magnetic nano-catalysts must meet some requirements to achieve a viable practical application, i.e., maintaining constant activity over time and adequate physical, chemical and mechanical stability. However, the nature of magnetic nanoparticles (MNPs) results in interparticle interactions, leading to the formation of large aggregates with a lower surface-to-volume ratio [15]. This drawback can be avoided by modifying the surface of MNPs with stabilizing agents to prevent aggregation of nanocatalysts due to steric or electrostatic forces [16]. Besides colloidal stability of the nanoparticles, the coating process can modify the surface of MNPs to prevent oxidation, to modify adsorption, or to increase the reusability. However, the coating might also hinder the catalytic activity of the MNPs. In this line, a recent review compiled the different advantages and limitations of organic coatings for magnetic nanoparticles [17].

Moreover, the immobilization of nanoparticles on a porous solid is of particular interest to facilitate the access of $\mathrm{H}_{2} \mathrm{O}_{2}$ to the active center of the catalyst as well as to improve its dispersion and separability [18]. Some novel approaches studied MNP immobilization onto different supports, such as cellulose nanofibers [19] or polydopamine matrices [20], resulting in improved degradation of organic pollutants and increased stability and recyclability compared to unsupported MNPs. In this context, the mesoporous silica matrix SBA15 has been used as an immobilization support for nanocatalysts in the field of wastewater treatment [21] as well as in organic synthesis [22], due to its porosity, chemical stability and facile and cost-effective synthesis. Its hexagonally arranged uniform channels with narrow pore size distribution, thick pore walls, high surface area and hydrothermal stability make it suitable for the immobilization of nanostructured catalysts.

In this manuscript, the use of different types of MNPs as efficient heterogeneous Fenton-like catalyst for the oxidation of different types of pollutants is explored, considering the influence of different coatings (PAA, PEI and $\mathrm{SiO}_{2}$ ) and a mesoporous support (SBA15) on the efficiency of the process and the stability of the nanoparticles. A first phase of nanocatalyst selection is proposed based on their dye removal capacity in order to define the optimization strategy for those options with the best performance results for the removal of endocrine disrupting chemicals -estrone (E1), 17 $\beta$-estradiol (E2) and $17 \alpha$ ethinylestradiol (EE2).

\section{Materials and Methods}

\subsection{Chemicals}

All chemicals were purchased from commercial suppliers. For the synthesis of the nanocatalysts, tetraethyl orthosilicate (TEOS, 98\%), polyethyleneimine (PEI, branched, average Mw $25 \mathrm{kDa}$ ), polyacrylic acid (PAA, average Mw $2 \mathrm{kDa}$ ), triblock copolymer Pluronic P123 (PEO20-PPO70-PEO20), iron(III) chloride hexahydrate $\left(\mathrm{FeCl}_{3} \cdot 6 \mathrm{H}_{2} \mathrm{O}, 97 \%\right.$ ), hydrochloric acid $(\mathrm{HCl}, 37 \%)$, cyclohexane $\left(\mathrm{C}_{6} \mathrm{H}_{12}, 99.8 \%\right)$, Igepal $\mathrm{CO}-520$ (polyoxyethylene (5) nonylphenylether, branched), isooctane $\left(\mathrm{C}_{8} \mathrm{H}_{18}, \geq 99 \%\right)$ and isopropanol $\left(\mathrm{C}_{3} \mathrm{H}_{8} \mathrm{O}\right.$, $\geq 99.5 \%$ ) were obtained from Sigma-Aldrich (St. Louis, MI, USA); hydrogen peroxide $\left(\mathrm{H}_{2} \mathrm{O}_{2}, 30 \% w / w\right)$ from Panreac Química SLU (Barcelona, Spain); iron(II) sulfate hep- 
tahydrate $\left(\mathrm{FeSO}_{4} \cdot 7 \mathrm{H}_{2} \mathrm{O}, 99 \%\right)$, tetramethylammonium hydroxide (TMAOH, $\left.\approx 10 w / w\right)$ ortho-phosphoric acid $\left(\mathrm{H}_{3} \mathrm{PO}_{4}, 85 \%\right)$ and ammonium hydroxide $\left(\mathrm{NH}_{4} \mathrm{OH}, 28 \%\right)$ from Fluka (Buchs, Switzerland), ethanol $\left(\mathrm{C}_{2} \mathrm{H}_{5} \mathrm{OH}, 99.9 \%\right)$ and acetone $\left(\mathrm{C}_{3} \mathrm{H}_{6} \mathrm{O}, \geq 99 \%\right)$ were purchased from Fischer (Waltam, MA, USA) and oleic acid (extra pure) from Merck (Kenilworth, NY, USA). Milli-Q deionized water (Millipore, Burlington, MA, USA) was used to prepare the different solutions and reaction media. Hydrogen peroxide $\left(\mathrm{H}_{2} \mathrm{O}_{2}, 30 \%\right)$, Reactive Blue 19 (RB19, 50\%), methyl green (MG, 85\%), estrone (E1, $\geq 99 \%), 17 \beta$-estradiol $(\mathrm{E} 2, \geq 98 \%)$ and $17 \alpha$-ethinylestradiol (EE2, $\geq 98 \%$ ) were purchased from Sigma-Aldrich (St. Louis, MI, USA).

\subsection{Synthesis of Nanostructured Catalysts}

\subsubsection{Preparation of Sterically Stabilized Magnetite}

Sterically stabilized magnetic $\mathrm{Fe}_{3} \mathrm{O}_{4}$ nanoparticles were prepared by coprecipitation of $\mathrm{Fe}(\mathrm{II})$ and $\mathrm{Fe}(\mathrm{III})$ salts, following the Massart's method [23]. The synthesis procedure required $12.15 \mathrm{~g}$ of $\mathrm{FeCl}_{3} \cdot 6 \mathrm{H}_{2} \mathrm{O}(45 \mathrm{mmol})$ and $8.35 \mathrm{~g}$ of $\mathrm{FeSO}_{4} \cdot 7 \mathrm{H}_{2} \mathrm{O}(30 \mathrm{mmol})$, with a molar ratio of $\mathrm{Fe}(\mathrm{III}) / \mathrm{Fe}(\mathrm{II}) \approx 1.5$, mixture to which $100 \mathrm{~mL}$ of $0.01 \mathrm{M} \mathrm{HCl}$ solution is added in a $250 \mathrm{~mL}$ round bottom flask. Once the salts were dissolved, the temperature was increased to $60{ }^{\circ} \mathrm{C}$ and $30 \mathrm{~mL}$ of $28 \% \mathrm{w} / \mathrm{w}$ ammonium hydroxide solution was added to the mixture, with immediate formation of black magnetite nanoparticles. The reaction was allowed to continue for $1 \mathrm{~h}$ at $60^{\circ} \mathrm{C}$ and the resulting precipitate was acidified to $\mathrm{pH} 4$ with $\mathrm{HCl}(9 \% w / w)$ and then magnetically separated. The nanoparticles were washed four times with deionized water and finally a $10 \% w / w$ TMAOH solution was added at $\mathrm{pH} 10$ to sterically stabilize the magnetite nanoparticles.

\subsubsection{Preparation of Poly(Ethyleneimine)-Coated Magnetite and Poly(Acrylic Acid)-Coated Magnetite Nanoparticles}

Poly(ethyleneimine)-coated $\left(\mathrm{Fe}_{3} \mathrm{O}_{4} @ \mathrm{PEI}\right)$ and poly(acrylic acid)-coated $\left(\mathrm{Fe}_{3} \mathrm{O}_{4} @ \mathrm{PAA}\right)$ MNPs were prepared with $2 \mathrm{~g}$ of PEI or PAA during the synthesis of the $\mathrm{Fe}_{3} \mathrm{O}_{4}$ MNPs approximately one minute after the addition of ammonium hydroxide. After the reaction was completed, the sample was cooled down to room temperature, and the $\mathrm{pH}$ was adjusted to 4 with $\mathrm{HCl}$. Finally, the MNPs were magnetically separated, washed four times with deionized water and re-dispersed in water.

\subsubsection{Preparation of Silica-Coated Magnetite Nanoparticles}

This procedure starts with the formation of a water-in-oil microemulsion system [24]. For this purpose, bare $\mathrm{Fe}_{3} \mathrm{O}_{4}$ MNPs were exposed to oleic acid (OA) until flocculation occurred. The OA-coated $\mathrm{Fe}_{3} \mathrm{O}_{4} \mathrm{MNPs}\left(\mathrm{Fe}_{3} \mathrm{O}_{4} @ \mathrm{OA}\right)$ were washed twice with deionized water and dispersed in cyclohexane. Then, polyoxyethylene(5)nonylphenyl ether (Igepal CO-520) and cyclohexane were mechanically stirred for $15 \mathrm{~min}$ before adding $\mathrm{Fe}_{3} \mathrm{O}_{4} @ \mathrm{OA}$ MNPs $(0.5 \% w / w$ in cyclohexane). Finally, ammonium hydroxide solution and tetraethyl orthosilicate (TEOS) were added consecutively under stirring to form a transparent red reverse microemulsion until the reaction was complete after $16 \mathrm{~h}$. The core-shell nanoparticles were precipitated with isopropanol (IPA) to interrupt the reverse microemulsion and washed four times with IPA and deionized water. Finally, they were subjected to several cycles of centrifugation ( $9000 \mathrm{rpm}, 15 \mathrm{~min}$ ) and washing with deionized water until no foam was observed. Finally, the core-shell nanoparticles were redispersed in deionized water until further use.

\subsubsection{Preparation of the $\mathrm{Fe}_{3} \mathrm{O}_{4} @ P A A / S B A 15$ Nanocomposite}

The synthetic procedure used to obtain the SBA15 matrix based on the Colilla method [25] has been previously reported [26]. According to the synthesis procedure, a triblock copolymer Pluronic $\mathrm{P} 123\left(\mathrm{PEO}_{20}-\mathrm{PPO}_{70}-\mathrm{PEO}_{20}\right)$ was dissolved at $35^{\circ} \mathrm{C}$ in a mixture of deionized water and $\mathrm{HCl}$. TEOS was then added to give a final molar composition of $1.0 \mathrm{M}^{\circ} \mathrm{SiO}_{2}$, $0.017 \mathrm{M}$ of P123 and 3.4 M HCl. The reaction was continued under magnetic stirring 
for $24 \mathrm{~h}$, followed by a curing step at $100^{\circ} \mathrm{C}$ for $24 \mathrm{~h}$; the resulting gel was collected by filtration. Finally, the product was dried and subjected to different washing cycles with organic solvents to remove the remaining block copolymer.

$\mathrm{Fe}_{3} \mathrm{O}_{4} @$ PAA/SBA15 nanocomposites were synthesized as previously described by Vargas-Osorio et al. [27] by incorporating $1 \mathrm{~g}$ of the SBA15 mesoporous matrix into a flask containing $19 \mathrm{~mL}$ of an aqueous solution of $0.01 \mathrm{M} \mathrm{HCl}, 1.2 \mathrm{~g}$ of hexahydrate ferric chloride and $0.8 \mathrm{~g}$ of tetrahydrate ferrous sulphate under mechanical stirring. The temperature was increased to $60{ }^{\circ} \mathrm{C}$ and $3.5 \mathrm{~mL}$ of ammonium hydroxide and $0.195 \mathrm{~g}$ of polyacrylic acid (PAA, Mw 2000) were added to the mixture $[23,28]$. The reaction was allowed to progress for one hour and the resulting precipitate was acidified to $\mathrm{pH} 4$ with $\mathrm{HCl}(9 \%)$ and then magnetically separated. Finally, it was repeatedly washed with distilled water and ethanol, and dried at $60^{\circ} \mathrm{C}$ for a period of $12 \mathrm{~h}$. A simplified scheme of the synthetic route for the preparation of $\mathrm{Fe}_{3} \mathrm{O}_{4} @ \mathrm{PAA} / \mathrm{SBA} 15$ is presented in the supplementary information (see Figure S1) for the sake of better understanding of the nanocatalyst preparation process.

\subsection{Characterization Methods}

The morphological study of the materials was characterized by scanning electron microscopy (SEM) using a Zeiss FE-SEM ULTRA Plus microscopy (Oberkochen, Germany) and a JEOL JEM-1011 transmission electron microscopy (TEM, Akishima, Tokio, Japan) using an accelerating voltage of $100 \mathrm{kV}$. Nanoparticle sizes were calculated from the micrographs using ImageJ software [29], with a minimum number of 100 measurements. The analysis of the crystalline phases was carried out by X-ray diffraction (XRD) on powder samples using a Philips PW1710 diffractometer $(\mathrm{Cu} \mathrm{K} \alpha$ radiation source, $\lambda=1.54186 \AA$ ) (Eindhoven, NB, The Netherlands). The measurements were collected in the $2 \theta$ angle between $10^{\circ}$ and $80^{\circ}$, increasing by $0.020^{\circ}$ and a time per step of $5 \mathrm{~s}$. The mesoporous matrix structure was analyzed by low-angle XRD in a PANalytical X'Pert Powder Empyrean, in a $2 \theta$ range between $0.25^{\circ}$ and $6^{\circ}$, and a step size of $0.01^{\circ}$ ( $5 \mathrm{~s}$ per step). Fourier transform infrared (FTIR) spectra were recorded in a Thermo Nicolet Nexus spectrometer using the attenuated total reflectance (ATR) method. Thermogravimetry was carried out using a Perkin Elmer TGA 7 thermobalance. The experiments were carried out under $\mathrm{N}_{2}$ at a heating rate of $10{ }^{\circ} \mathrm{C} \min ^{-1}$ up to $850{ }^{\circ} \mathrm{C}$ with a final isothermal step at $850{ }^{\circ} \mathrm{C}$ during $30 \mathrm{~min}$. Pore size distribution and specific surface area were estimated from $\mathrm{N}_{2}$ adsorption-desorption isotherms obtained using a Quantachrome Autosorb IQ2 instrument. Magnetization curves as a function of the applied magnetic field up to $10 \mathrm{kOe}$ were obtained at room temperature with a DMS 1660 vibrating sample magnetometer (VSM). The iron content of MNPs and effluents was determined by inductively coupled plasma optical emission spectroscopy (ICP-OES) using a Perkin-Elmer Optima 3300 DV equipped with an autosampler PerkinElmer AS91 (Waltham, MA, USA). Samples were directly measured without solid filtration or digestion. The zeta potential of nanoparticles and nanocomposites was measured at $\mathrm{pH}$ 3 using a Zetasizer NanoZS (Malvern Panalytical, Almelo, The Netherlands) equipment using the Phase Analysis Light Scattering (PALS) technique.

\subsection{Selection of Nanoparticles and Nanomaterials as Catalysts in Fenton-Type Reactions for Dye Oxidation}

Considering the non-specific reaction mechanisms of Fenton-based processes, dye removal was considered a good approach for the benchmarking of nanoparticles performance prepared with different coatings and nanocatalyst supports. The operating conditions are set after an initial screening using bare $\mathrm{Fe}_{3} \mathrm{O}_{4} \mathrm{MNPs}$ for $\mathrm{RB} 19$ removal at different conditions of initial concentrations of $\mathrm{H}_{2} \mathrm{O}_{2}\left(100-500 \mathrm{mg} \mathrm{L}^{-1}\right)$ and catalyst $\left(100-750 \mathrm{mg} \mathrm{L}^{-1}\right)$, with a fixed pH of 3 (see Figures S2 and S3 of the supplementary information). Based on the optimization results, a solution of Reactive Blue 19 (RB19) or Methyl Green (MG) with an initial concentration of $25 \mathrm{mg} \mathrm{L}^{-1}$ was degraded using $200 \mathrm{mg} \mathrm{L}^{-1}$ of the different nanoparticles and $100 \mathrm{mg} \mathrm{L}^{-1}$ of hydrogen peroxide at $\mathrm{pH} 3$.

Batch experiments were performed at room temperature and $150 \mathrm{rpm}$ in an orbital shaker (C24 Incubator shaker, New Brunswick Scientific, Edison, NJ, USA). The nanoparti- 
cles and the target compounds were mixed at the beginning of the experiments to achieve adsorption equilibrium, and the reaction was initiated after the addition of $100 \mathrm{mg} \mathrm{L}^{-1}$ of $\mathrm{H}_{2} \mathrm{O}_{2}$. At regular time intervals, absorbance measurements were performed to monitor the variation in the characteristic absorbance of the dyes (RB19, $\lambda_{\max }=592 \mathrm{~nm}$ and MG, $\lambda_{\max }=633 \mathrm{~nm}$ ) using a BioTek PowerWave XS2 micro-plate spectrophotometer. The decolorization yield (\%) was determined as the color disappearance rate, calculated by the following equation:

$$
\text { Degradation yield }(\%)=\left(\mathrm{C}_{0}-\mathrm{C}_{\mathrm{t}}\right) / \mathrm{C}_{0} \times 100 \text {, }
$$

where $C_{0}$ represents the initial dye concentration $\left(\mathrm{mg} \mathrm{L}^{-1}\right)$, and $\mathrm{C}_{\mathrm{t}}$ represents the concentration for a given time $(\mathrm{t})$. Additionally, in order to elucidate the influence of the MNPs on the dye removal, adsorption control experiments without $\mathrm{H}_{2} \mathrm{O}_{2}$ and control experiments with $\mathrm{H}_{2} \mathrm{O}_{2}$ dosage but lacking MNPs were conducted.

The reusability of the catalyst was evaluated in a sequential operation of a $10 \mathrm{~mL}$ reactor with magnetic separation of nanoparticles. After each Fenton-type cycle, the liquid fraction was withdrawn by separating the catalyst with an external magnetic field. Fresh medium containing RB19 or MG $\left(25 \mathrm{mg} \mathrm{L}^{-1}\right)$ was added to the reactor containing the catalyst for a new cycle. Aliquots were taken at the beginning and the end of each cycle to determine the dye concentration and percentage removal. The stability of the catalyst after five consecutive cycles was evaluated by determining the iron content in the liquid fraction by ICP-OES.

\subsection{Experimental Design for Estrogen Degradation}

The experiments of estrogen degradation were conducted in $10 \mathrm{~mL}$ reaction medium containing $100-1000 \mathrm{mg} \mathrm{L}^{-1}$ of mesoporous supported catalyst $\left(\mathrm{Fe}_{3} \mathrm{O}_{4} @ \mathrm{PAA} / \mathrm{SBA} 15\right)$ and variable concentrations of the estrogens E1, E2 and EE2 $\left(100-500 \mu \mathrm{g} \mathrm{L} \mathrm{L}^{-1}\right)$. Batch experiments were performed at room temperature and with continuous orbital shaking (150 rpm), pH values from 3 to 5 and different concentrations of $\mathrm{H}_{2} \mathrm{O}_{2}$ in the range of 200 to $500 \mathrm{mg} \mathrm{L}^{-1}$. At regular intervals, aliquots $(200 \mu \mathrm{L})$ were withdrawn to monitor the removal of estrogens. In addition, the degradation yield (\%) was determined using Equation (1), and parallel controls were carried out to evaluate the dye adsorption on the catalyst surface, the influence of $\mathrm{H}_{2} \mathrm{O}_{2}$ and $\mathrm{pH}$ stability to quantify the individual contributions.

The concentrations of estrogens were quantified by High Performance Liquid Chromatography (HPLC) at a detection wavelength of $278 \mathrm{~nm}$ on a Jasco XLC HPLC equipped with a 3110 MD diode array detector and a Gemini ${ }^{\circledR} 3 \mu \mathrm{m} \mathrm{C18} 110 \AA$ A reverse phase column $(150 \mathrm{~mm} \times 4.6 \mathrm{~mm})$ from Phenomenex (supplied by Jasco, Ishikawa, Japan) and an HP ChromNav data processor. The gradient elution flow $\left(0.8 \mathrm{~mL} \mathrm{~min}^{-1}\right)$ started with $20 \%$ acetonitrile in water followed by an increase to $90 \%$. The detection limits for the estrogens were $36.9 \mu \mathrm{g} \mathrm{L}^{-1}$ for E1, $29.2 \mu \mathrm{g} \mathrm{L}^{-1}$ for E2 and $36.0 \mu \mathrm{g} \mathrm{L}^{-1}$ for EE2. The correlation coefficients of the calibration lines $\left(\mathrm{R}^{2}\right)$ were greater than 0.99 .

\section{Results and Discussion}

\subsection{Catalyst Characterization}

The morphology and average particle size of $\mathrm{Fe}_{3} \mathrm{O}_{4}$ MNPs were analyzed by TEM microscopy (Figure S4). Bare $\mathrm{Fe}_{3} \mathrm{O}_{4}, \mathrm{Fe}_{3} \mathrm{O}_{4} @ \mathrm{PEI}$ and $\mathrm{Fe}_{3} \mathrm{O}_{4} @ \mathrm{PAA}$ are mainly spherical shaped particles with average diameters ranging from 7.6 to $10.9 \mathrm{~nm}$ (Table 1). The average particle size of $\mathrm{Fe}_{3} \mathrm{O}_{4} @ \mathrm{SiO}_{2} \mathrm{MNPs}$ increases to diameters of around $20 \mathrm{~nm}$, evidencing the remarkable effect of silica coating on the particle size, as noted by the color difference detected in TEM micrograph analyses. 
Table 1. Properties of the different nano-catalysts used in this work.

\begin{tabular}{lcccc}
\hline \multicolumn{1}{c}{ Catalyst } & Size $(\mathbf{n m})$ & $\left.\mathbf{S}_{\text {BET }}{ }^{\mathbf{1}}{\mathbf{( \mathbf { m } ^ { 2 }}}^{\mathbf{2}} \mathbf{g}^{-\mathbf{1}}\right)$ & $\mathbf{P S}_{\text {DFT }}{ }^{\mathbf{2}}(\mathbf{n m})$ & $\mathbf{Z P}^{\mathbf{3}}(\mathbf{m V})$ \\
\hline $\mathrm{Fe}_{3} \mathrm{O}_{4}$ & $8.2 \pm 3.8$ & - & - & -11.54 \\
$\mathrm{Fe}_{3} \mathrm{O}_{4} @$ PEI & $10.9 \pm 3.0$ & - & - & 29.94 \\
$\mathrm{Fe}_{3} \mathrm{O}_{4} @ \mathrm{PAA}$ & $7.6 \pm 2.7$ & - & - & -4.53 \\
$\mathrm{Fe}_{3} \mathrm{O}_{4} @ \mathrm{SiO}_{2}$ & $20.2 \pm 4.2$ & - & - & -14.28 \\
$\mathrm{Fe}_{3} \mathrm{O}_{4} @ \mathrm{PAA} / \mathrm{SBA} 15$ & $>1000$ & 276.9 & 7.59 & -1.47 \\
\hline
\end{tabular}

${ }^{1} \mathrm{~S}_{\mathrm{BET}}$ : BET specific surface area, ${ }^{2} \mathrm{PS}_{\mathrm{DFT}}$ : pore size, ${ }^{3} \mathrm{ZP}$ : zeta potential.

The morphology of the $\mathrm{Fe}_{3} \mathrm{O}_{4} @ \mathrm{PAA} / \mathrm{SBA} 15$ nanocomposite was also analyzed by SEM and TEM. Considering the synthesis procedure of SBA15, the use of a triblock copolymer (P123) allows to obtain large pore diameters $(4-10 \mathrm{~nm})$ and thick walls; thus, producing a stable material. Figure 1 shows the hexagonal structure of the mesoporous silica matrix in which the magnetite nanoparticles have been deposited, forming small aggregates (clear dots) distributed along its surface and predictably within the mesoporous silica channels.

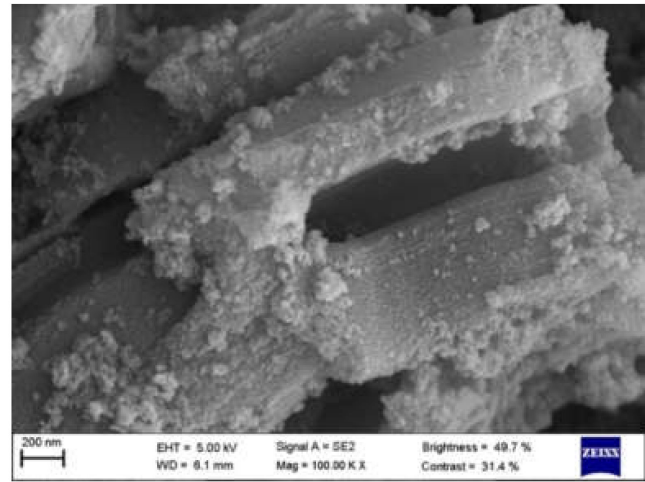

(a)

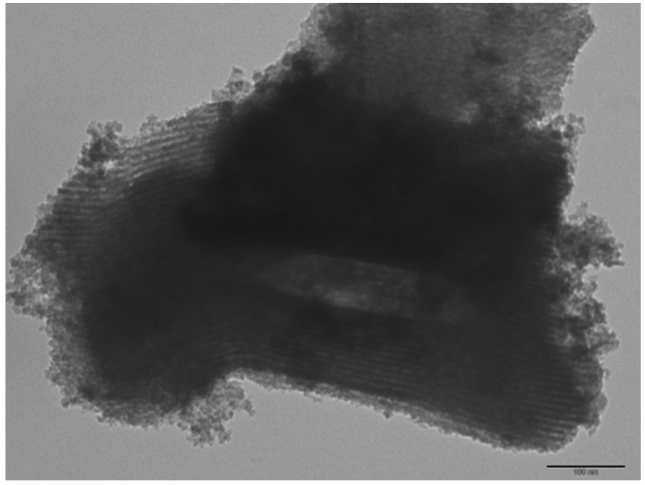

(b)

Figure 1. (a) SEM and (b) TEM micrographs of $\mathrm{Fe}_{3} \mathrm{O}_{4} @ \mathrm{PAA} / \mathrm{SBA} 15$. Scale bar on the TEM image corresponds to $100 \mathrm{~nm}$.

Additional nanoparticle and SBA15 matrix characterization data are presented in Table 1. The size of the mesoporous matrix is in the micrometer range, which is much larger compared to the rest of the nanoparticles considered, which have sizes ranging from 10 to $30 \mathrm{~nm}$. Moreover, the zeta potential of the nanoparticles, essential to predict the stability of the nanoparticles and the interactions between the materials and the target compounds, corresponded to negative values at $\mathrm{pH} 3$ (experimental conditions of the Fenton-based reactions). In the case of the mesoporous matrix, the pore size distribution and the specific surface area were estimated from the type IV adsorption isotherms that are characteristic of mesoporous materials (Figure S5). The boundary hysteresis loop with two-level parallel branches (type H1) confirmed the presence of cylindrical pores in the matrix.

The formation of magnetite by the described synthetic procedures was confirmed by analyzing the crystalline phases present in the MNPs using XRD. $\mathrm{Fe}_{3} \mathrm{O}_{4}, \mathrm{Fe}_{3} \mathrm{O}_{4} @ \mathrm{SiO}_{2}$, $\mathrm{Fe}_{3} \mathrm{O}_{4} @ \mathrm{PEI}$ and $\mathrm{Fe}_{3} \mathrm{O}_{4} @ \mathrm{PAA}$ MNPs showed magnetite in crystalline phase as shown in Figure 6 , which presents an inverse spinel structure $\left(\mathrm{Fe}_{3} \mathrm{O}_{4}\right.$, JCPDS PDF-2 card number 19-0629), while $\mathrm{Fe}_{3} \mathrm{O}_{4} @ \mathrm{SiO}_{2}$ showed a broad band between $18^{\circ}$ and $29^{\circ}$ corresponding to the amorphous silica coating [30]. The structure of the MNPs supported on the mesoporous matrix was evaluated by low-angle XRD (see Figure S7). The alteration of the structural arrangement of SBA15 with the disappearance of (110) and (200) reflections is related to the random distribution of $\mathrm{Fe}_{3} \mathrm{O}_{4}$ MNPs in the nanocomposite, leading to a partial loss of the long-range hexagonal order [31]. PAA coating of the magnetite in the nanocomposite was confirmed by ATR and TGA analysis. Figure S8 show the infrared spectrum of $\mathrm{Fe}_{3} \mathrm{O}_{4} @ \mathrm{PAA} / \mathrm{SBA} 15$, showing a characteristic peak between $1700-1720 \mathrm{~cm}^{-1}$, assigned to 
the $\mathrm{C}=\mathrm{O}$ bond of PAA. The thermogravimetric analysis presented in Figure S9 showed a mass loss of about $12 \%$ after water evaporation. However, this mass loss cannot be directly used to quantify the amount of PAA in the nanocomposite, as a small quantity of unwashed surfactant from SBA15 synthesis is being degraded in the same temperature range.

Magnetization studies of $\mathrm{Fe}_{3} \mathrm{O}_{4}$ MNPs and magnetic nanocomposites were performed by measuring the variation of magnetization as a function of the applied magnetic field at $300 \mathrm{~K}$, showing a clear superparamagnetic behavior (negligible coercive forces and remanence) for all samples analyzed (Figure S10). The magnetization properties of the studied MNPs are suitable for magnetic separation from a liquid matrix, being similar to those obtained by other authors in the synthesis of SBA15-based catalysts for Fenton reactions [32].

\subsection{Preliminary Screening of Nanocatalysts for RB19 and MG Removal}

A preliminary screening of different types of magnetite-based nanocatalysts was carried out based on the dye removal performance according to Fenton-type reactions as recommended in different literature reports. Accordingly, a set of experiments is performed on samples containing $25 \mathrm{mg} \mathrm{L}^{-1}$ of two model dyes: Reactive Blue 19 (RB19) and Methyl Green (MG), which present different chemical structure and types of chromophores. In particular, RB19 is an anionic anthraquinone dye, while MG is a cationic arylmethane dye. The variation in charge and structure of the molecules informs about the potential of the MNPs to target the removal of compounds with different chemical properties.

The control experiments containing $\mathrm{H}_{2} \mathrm{O}_{2}$ in the absence of a catalyst resulted in low degradation percentages of $13.6 \%$ and $1.6 \%$ for RB19 and MG, respectively. Following the same trend, the tests evaluating the adsorption of the dyes onto the nanocatalysts showed no significant decrease in dye concentration except for the adsorption of RB19 by PEI-coated magnetite where adsorption is the main contributing factor. Based on the color removal results, the potential of Fenton-type reactions associated with nanomaterials in dye removal is proven. The differences between the removal rates of the degradation and control experiments confirm the suitability of the selected dyes as model compounds.

The effect of the different coatings on $\mathrm{Fe}_{3} \mathrm{O}_{4} \mathrm{MNPs}\left(\mathrm{SiO}_{2}, \mathrm{PAA}\right.$ and PEI) on dye removal was evaluated and compared with bare magnetite, as depicted in Figure 2, resulting in a reduction of the catalytic activity of the bare magnetite. The removal rates obtained using bare nanoparticles were $78 \%$ and $40 \%$ for RB19 and $\mathrm{MG}$, respectively. When $\mathrm{SiO}_{2}$ coating was evaluated, these values decreased to $22 \%$ and $20 \%$, with no difference in the adsorption values achieved; thus, this modification significantly decreased the removal values. This decrease is probably caused by the amorphous structure of silica around the nanoparticle limiting molecule access to the catalyst surface, reducing the removal efficiency. Conversely, both PAA and PEI coating increased the adsorption capacity of the catalysts for both dyes, however the removal percentages were lower than those obtained for bare magnetite. The use of polyelectrolytes such as PAA and PEI for nanoparticles covering causes the appearance of electrostatic and steric interactions, that could affect to the dye adsorption and consequently to the removal efficiency. Although the interactions between hydrogen peroxide and covering probably was negligible due to their low molecular weight, these interactions could be magnified for heavier molecules as dyes [33]. Although PEI-coated nanoparticles showed similar removal values in terms of RB19, the decrease in concentration is mainly caused by adsorption and not only by catalytic degradation. From the comparison of the three supports evaluated, the PAA coating resulted in a slight decrease (between 10-15\% for both dyes) of the degradation capacity of the bare magnetite, thus resulting in the most suitable strategy for nano-catalyst stabilization. 


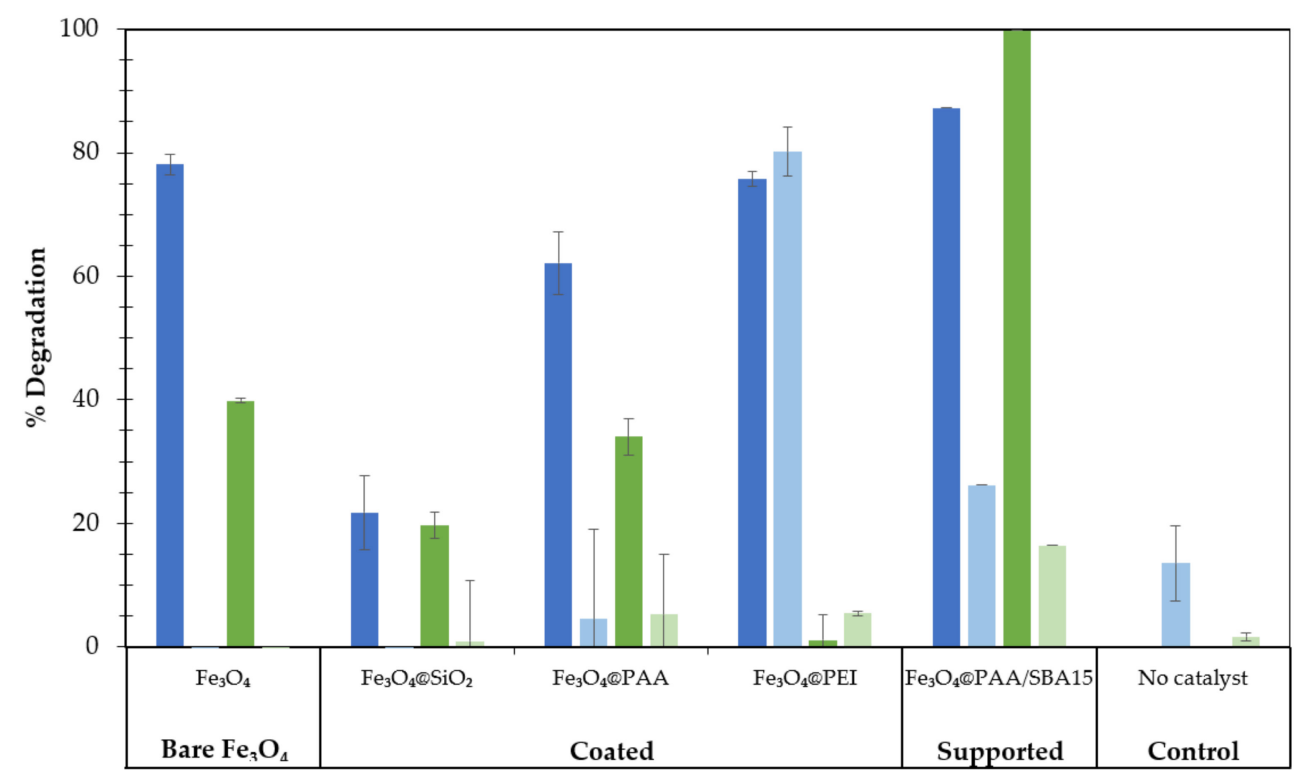

Figure 2. Percentage of dye decolorization (dark bars) and control experiments (light bars) for RB19 after $2 \mathrm{~h}$ (blue) and for MG after $4 \mathrm{~h}$ of reaction (green), using different $\mathrm{Fe}_{3} \mathrm{O}_{4}$-stabilized MNPs as heterogeneous Fenton catalysts. Operational conditions: $[\mathrm{Fe}]=200 \mathrm{mg} \mathrm{L}^{-1},\left[\mathrm{H}_{2} \mathrm{O}_{2}\right]=100 \mathrm{mg} \mathrm{L}^{-1}$, $\mathrm{pH} 3, \mathrm{~V}=10 \mathrm{~mL}$.

Differences between the adsorption values of MG and RB19 are probably caused by the differences in zeta potential using different coatings. The effects of coating on MNPs with different types of polymers (such as PAA or PEI) or $\mathrm{SiO}_{2}$ alter the surface charge by modifying the interactions between the degradation targets and the catalysts. This phenomenon could explain the high adsorption values of RB19 (negative charge) on PEIcoated magnetite (high positive zeta potential) and the moderate adsorption values for the other type of nanoparticles, with absolute surface charges below $15 \mathrm{mV}$. Furthermore, negative zeta potential values were reportedly shown to contribute to $\mathrm{H}_{2} \mathrm{O}_{2}$ decomposition, favoring the concentration of $\mathrm{H}_{3} \mathrm{O}^{+}$near the surface and promoting radical formation [34]. However, the high interaction between PEI-coated magnetite and RB19 is not related to high degradation rates, as a high adsorption value may lead to saturation of the catalyst surface and consequently, to slower kinetics. According to preliminary results, zeta potential values close to zero and negative seem to enhance the removal of the target compounds.

Based on the dye degradation results, the type of nanoparticle selected was $\mathrm{Fe}_{3} \mathrm{O}_{4} @ \mathrm{PAA}$, which was subsequently immobilized on the mesoporous matrix. As seen in Figure 2, the use of mesoporous support greatly increases the efficiency of the Fenton process, as the best overall removal percentages for RB19 and MG were achieved using PAA-coated magnetite nanoparticles supported in a mesoporous silica matrix $\left(\mathrm{Fe}_{3} \mathrm{O}_{4} @ \mathrm{PAA} / \mathrm{SBA} 15\right)$. Comparing the results with those of bare magnetite, the main difference is observed for MG removal, reaching a significant increase in performance (around 60\% removal), while in terms of RB19 removal, an increase of around 10\% was observed when using the mesoporous support. Adsorption control experiments showed a significant increase in adsorption values on SBA15-compatible nanoparticles that could be caused by the enhanced surface area of the mesoporous support. The enhancement of catalysts by immobilization on mesoporous silica was also studied by other authors [32,35], also concluding that the use of a mesoporous support improves the catalytic performance by increasing the surface areas and favoring the dispersity of MNPs.

One of the requirements to be met by the proposed process is the efficiency of reuse of the MNPs in order to ensure the safe retention of the nanocatalyst and its subsequent use in sequential batch cycles. Degradation efficiency is not the only factor to be considered to ensure the viability of the process, as losses of nanocatalyst after poor separation not only 
consume an essential resource and affect the economics of the process but may also pose problems of iron presence in the treated effluent and may require a subsequent purification process to avoid the risks associated with the discharge of this type of material. Figure 3 shows the dye removal after five consecutive cycles for bare magnetite, PAA-coated and supported nanoparticles with nano-catalyst recovery performed by external magnetic separation and with no catalyst regeneration between cycles.

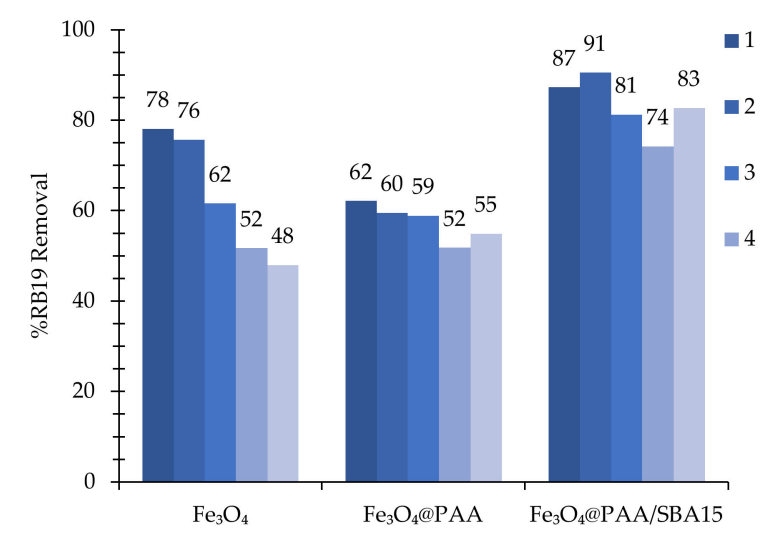

(a)

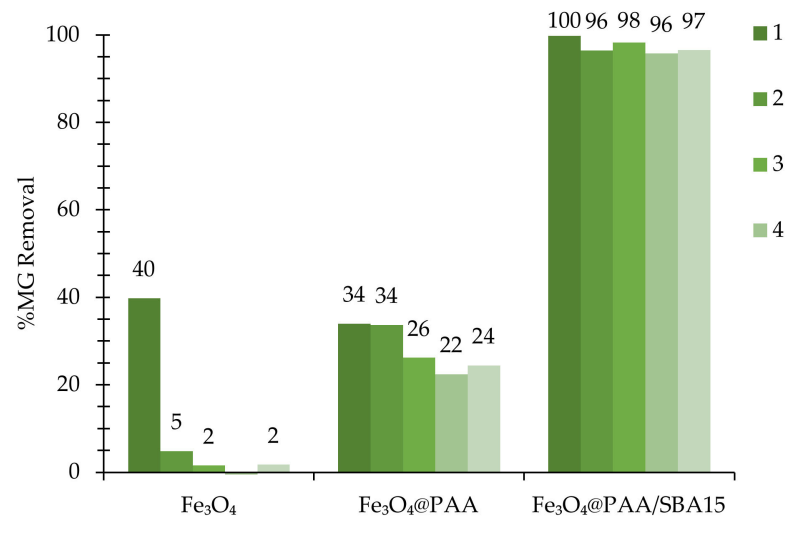

(b)

Figure 3. Evaluation of the reusability of $\mathrm{Fe}_{3} \mathrm{O}_{4}$-based MNPs over 5 cycles in the degradation of (a) RB19 and (b) MG.

Although the addition of PAA as a coating agent shows a lower degradation value in the first cycle compared to bare magnetite, the efficiency of the process in the subsequent cycles is clearly aided by the coating due to the stabilization of the MNPs. The bare magnetite nanoparticles showed a 40\% reduction in activity for RB19 removal after 5 cycles, while MG removal under the same conditions decreased to below $5 \%$ of the total degradation already by the second cycle. In contrast, the PAA-coated nanocatalyst showed lower decay rates, presenting a 10\% and 30\% reduction of the removal efficiencies for RB19 and MG, respectively. The addition of a mesoporous silica matrix allowed to increase the removal rates for both RB19 and MG, as well as to reduce the decay values to below 5\% when comparing the degradation values for the first and the last cycles.

The recovery of MNPs after the degradation cycles was quantified by analyzing the presence of iron in the treated effluent after the magnetic separation of the effluent after the fifth cycle. Characterization of the effluent after ICP-OES determination provided recovery values of $28.1 \pm 3.6 \%$ for the bare nanoparticles, these values were increased for the PAA-coating ones to reach a recovery of $86.3 \pm 4.1 \%$ after five cycles. For the SBA15-supported catalyst, the recovery value of $84.0 \pm 2.8 \%$ shows a similar performance compared to $\mathrm{Fe}_{3} \mathrm{O}_{4} @ \mathrm{PAA}$. Although the main factors affecting the recovery of MNPs are their magnetic properties, size and zeta potential, other factors such as agglomeration or matrix composition could influence this factor. Considering iron losses, the most easily separable catalysts were $\mathrm{Fe}_{3} \mathrm{O}_{4} @ \mathrm{PAA}$ and $\mathrm{Fe}_{3} \mathrm{O}_{4} @ \mathrm{PAA} / \mathrm{SBA} 15$ nanoparticles. Although the magnetization values of the SBA15-supported nanoparticles are lower than the nonsupported ones, their higher size and a similar or lower values of zeta potential could contribute to a better separation.

\subsection{Heterogeneous Fenton Removal for Estrogens Using $\mathrm{Fe}_{3} \mathrm{O}_{4} @ P A A / S B A 15$}

The nanomaterial $\mathrm{Fe}_{3} \mathrm{O}_{4} @ \mathrm{PAA} / \mathrm{SBA} 15$ was considered for further characterization studies on estrogen removal due to the excellent results obtained in dye removal experiments in batch operation and in sequential cycles. According to the results obtained under the conditions defined in the previous experiments, the estrogen removal percentages reached levels close to $40 \%$ after $6 \mathrm{~h}$ of treatment, demonstrating the higher relative stability of this type of compounds against hydroxyl and/or superoxide radicals in the Fenton 
reaction. Consequently, the reaction conditions for the oxidative degradation of estrogens in the presence of $\mathrm{Fe}_{3} \mathrm{O}_{4} @ P A A / S B A 15$ were optimized as a function of catalyst and $\mathrm{H}_{2} \mathrm{O}_{2}$ concentration as well as the $\mathrm{pH}$ of the reaction medium.

The effect of $\mathrm{Fe}_{3} \mathrm{O}_{4} @ \mathrm{PAA} / \mathrm{SBA} 15$ concentration in the samples was evaluated in the range of $100-1000 \mathrm{mg} \mathrm{L}^{-1}$, to degrade E1, E2 and EE2 $\left(C_{0}=350 \mu \mathrm{g} \mathrm{L}^{-1}\right)$ in the presence of $\mathrm{H}_{2} \mathrm{O}_{2}\left(300 \mathrm{mg} \mathrm{L}^{-1}\right)$ at $\mathrm{pH}$ 3. The catalytic efficiency was found to increase with catalyst concentration up to $750 \mathrm{mg} \mathrm{L}^{-1}$, obtaining degradation rates of $83 \%$ (E1), $91 \%$ (E2) and $90 \%$ (EE2) (Figure 4). Beyond this optimum value, the catalytic efficiency gradually decreased, which can be attributed to the aggregation of the nanocomposite and, consequently, the decrease of the active surface. This behavior was observed by other authors in Fentontype processes when the catalyst loading reached an upper limit; however, this limit varies depending on different factors such as $\mathrm{H}_{2} \mathrm{O}_{2}$ concentration or catalyst type [36,37]. In addition, high concentration of ferrous ions was observed to be a factor causing the scavenging of hydroxyl radicals [38]. The adsorption control samples showed the same trend, with higher rates at $750 \mathrm{mg} \mathrm{L}^{-1}$ of nanocomposite, however the contribution of this parameter to the total degradation is not significant, accounting for $5 \%$ of the total removal. The contribution of iron concentration below $750 \mathrm{mg} \mathrm{L}^{-1}$ follows a linear trend, showing an average increase of about $10 \%$ for each increase of $100 \mathrm{mg} \mathrm{L}^{-1}$ in the catalyst concentration.

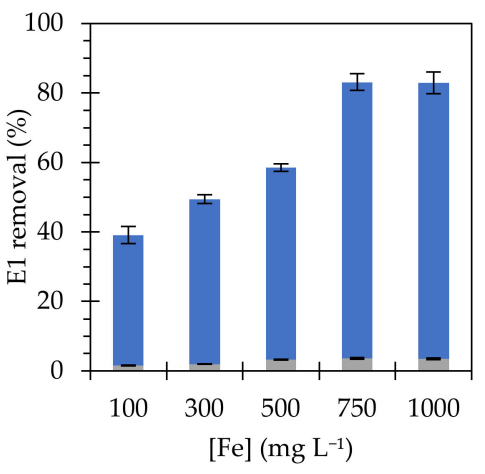

(a)

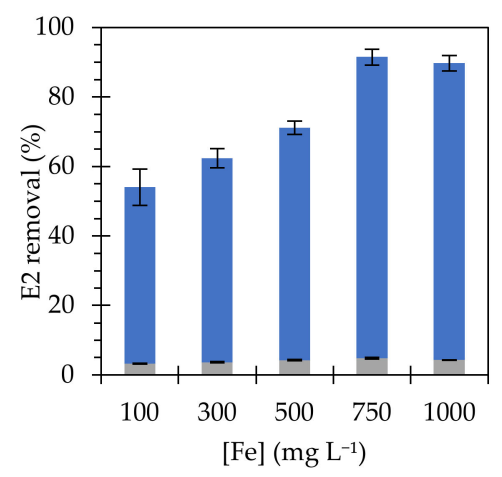

(b)

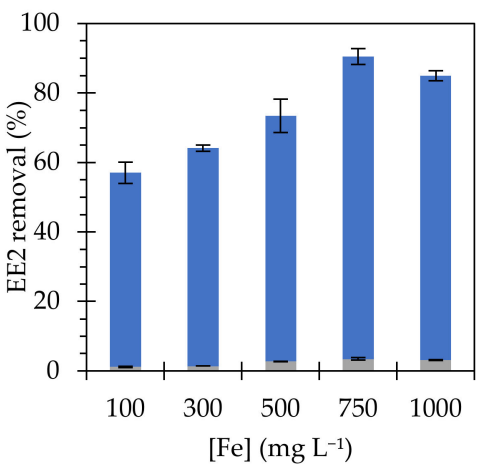

(c)

Figure 4. Effect of Fe concentration on the removal of (a) E1, (b) E2 and (c) EE2 (initial concentration of $350 \mu \mathrm{g} \mathrm{L} \mathrm{L}^{-1}$ ), using $\mathrm{Fe}_{3} \mathrm{O}_{4} @ P A A / S B A 15$, after $6 \mathrm{~h}$. Blue bars represent estrogen removal by Fenton reactions; grey bars represent estrogen removal by adsorption.

Optimization of the $\mathrm{H}_{2} \mathrm{O}_{2}$ dosage was studied using the optimal catalyst concentration of $750 \mathrm{mg} \mathrm{L}^{-1}$ obtained in the previous step. The results shown in Figure 5 indicate that high concentrations of $\mathrm{H}_{2} \mathrm{O}_{2}$ implied removal percentages lower than expected due to the role of $\mathrm{H}_{2} \mathrm{O}_{2}$ as scavenger in radical production, as previously reported for ferromagnetic nanoparticles [36] and for different types of Fenton catalysts [37,39]. Hydrogen peroxide concentration does not have a large impact on the degradation of estrogens, since variations of $20 \%$ were observed between worst and best values, achieved for 200 and $400 \mathrm{mg} \mathrm{L}^{-1}$, respectively. The removal percentages have similar values independently of the type of estrogen, reaching slightly higher values for estradiol. In addition, the control experiments provided low degradation yields, showing that the major contribution to the removal is due to the catalytic mechanism. The reactions between the formed radicals and hydrogen caused a scavenging effect and consequently a negative effect on radical production $[40,41]$. Considering a concentration of $750 \mathrm{mg} \mathrm{L}^{-1}$ of catalyst, the best yields were achieved for $400 \mathrm{mg} \mathrm{L}^{-1}$ of $\mathrm{H}_{2} \mathrm{O}_{2}$. 


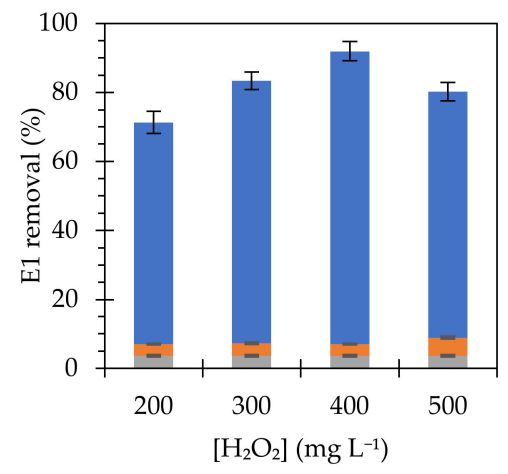

(a)

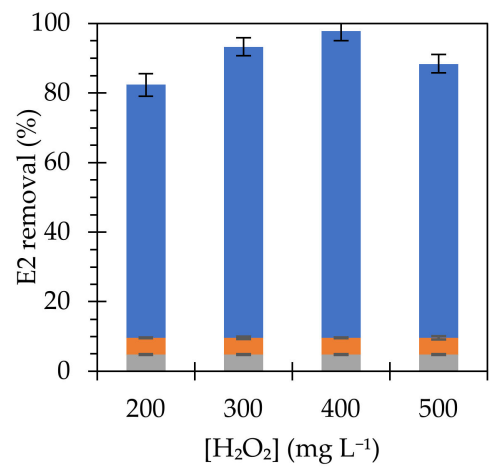

(b)

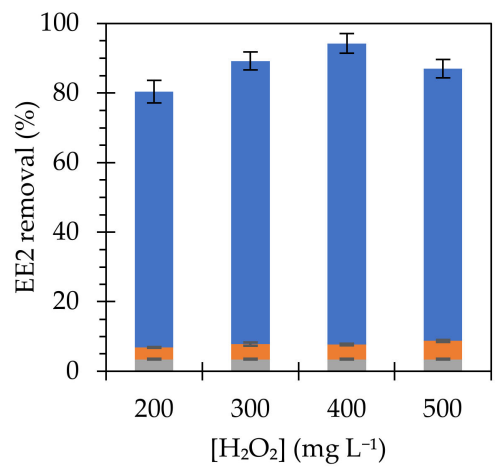

(c)

Figure 5. Effect of $\mathrm{H}_{2} \mathrm{O}_{2}$ concentration on the removal of (a) E1, (b) E2 and (c) EE2 (initial concentration of $350 \mu \mathrm{g} \mathrm{L}-1$ ), using $\mathrm{Fe}_{3} \mathrm{O}_{4} @ \mathrm{PAA} / \mathrm{SBA} 15$ with $[\mathrm{Fe}]$ at $750 \mathrm{mg} \mathrm{L}^{-1}$ after $6 \mathrm{~h}$. Blue bars represent estrogen removal by Fenton reactions; grey bars represent estrogen removal by adsorption; orange bars represent $\mathrm{H}_{2} \mathrm{O}_{2}$ controls.

Finally, the influence of $\mathrm{pH}$ was studied to analyze the degradation of target compounds under variable acidic conditions. Although it is well known that Fenton reactions are favored at $\mathrm{pH}$ around 3 [10], it is advisable to evaluate the feasibility of increasing the $\mathrm{pH}$ of the medium if an environmental application is pursued. Consequently, estrogen removal was investigated at a $\mathrm{pH}$ range of 3 to 5 (Figure 6).

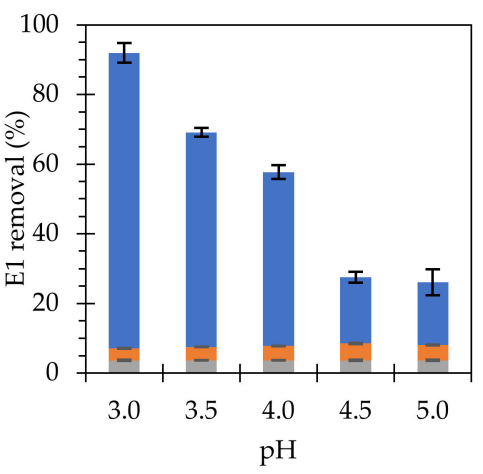

(a)

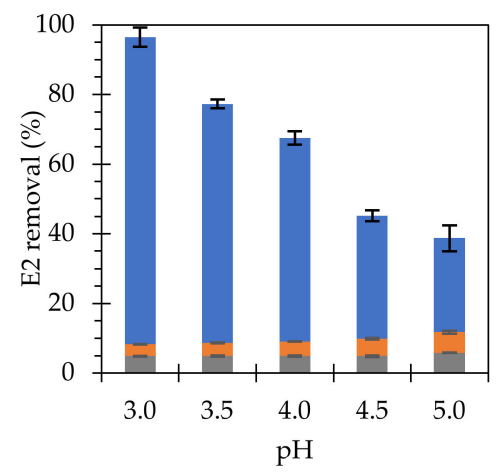

(b)

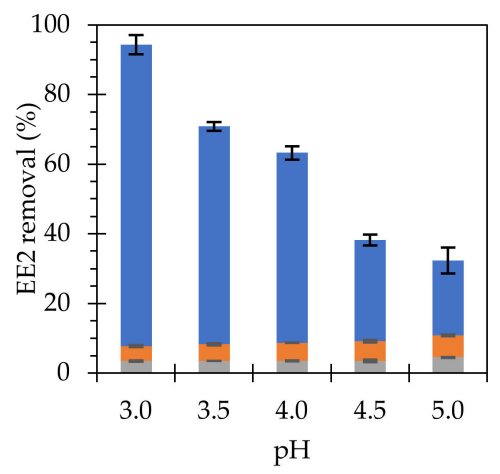

(c)

Figure 6. Effect of $\mathrm{pH}$ on the removal of (a) E1, (b) E2 and (c) EE2 (initial concentration of $350 \mu \mathrm{g} \mathrm{L}^{-1}$ ), using [Fe] at $750 \mathrm{mg} \mathrm{L}^{-1}$ and $\mathrm{H}_{2} \mathrm{O}_{2}$ at $300 \mathrm{mg} \mathrm{L}^{-1}$ after $6 \mathrm{~h}$. Blue bars represent estrogen removal by Fenton reactions; grey bars represent estrogen removal by adsorption; orange bars represent $\mathrm{H}_{2} \mathrm{O}_{2}$ controls.

A gradual and sustained reduction in removal rates was observed as the $\mathrm{pH}$ increased from the optimum value of 3 . The total reduction in removal rates was approximately $75 \%$ when comparing the initial values with those obtained for $\mathrm{pH} 5$. The control experiments followed a similar trend as for $\mathrm{H}_{2} \mathrm{O}_{2}$ studies. Significant removal rates were not detected at these control tests, concluding that the main removal mechanism is the Fenton catalysis. In concordance to the previous experiments, the elimination percentage observed for E2 was higher than the obtained for E1 and EE2, although the differences are lower compared to the absolute removal ratios. Similar trends were observed by other authors when investigating the influence of $\mathrm{pH}$ on the degradation of different types of compounds, using similar degradation mechanisms based on the decomposition of hydrogen peroxide to form hydroxyl radicals. As a general trend, the kinetics decreased significantly when $\mathrm{pH}$ values exceeded the upper limit of 4.5 [39,42]. In addition, there were no significant changes in the hydrogen peroxide and adsorption controls under the different experimental conditions.

The optimum result of iron concentration is higher than the values reported by other authors applying homogeneous Fenton $[43,44]$. The increase of iron concentration is re- 
lated to the use of heterogeneous catalysts, where the contact between the degradation targets and the iron present in the catalyst is limited. Therefore, the use of higher iron concentrations does not represent a drawback for the application of the process since the magnetic properties of the catalyst allow its reuse and avoid the increase of iron species in the effluent. In addition, another advantage on the use of heterogeneous catalysts is that the increase in $\mathrm{pH}$ values does not require the use of stabilizing agents, such as ethylenediaminetetraacetic acid (EDTA) or ethylenediamine- $\mathrm{N}, \mathrm{N}^{\prime}$-disuccinic acid (EDDS), to stabilize the iron in solution. Regarding the ratio of hydrogen peroxide and catalyst concentrations and the results obtained, the optimal ratio is approximately $1: 2$ of $\left[\mathrm{H}_{2} \mathrm{O}_{2}\right]$ :[Fe]. When it comes to identifying the contribution of adsorption and $\mathrm{H}_{2} \mathrm{O}_{2}$ addition, the controls showed no significant contribution to the total degradation, with total values below $10 \%$.

\subsection{Determination of Kinetic Parameters for Estrogen Removal}

Further analysis of estrogen degradation using $\mathrm{Fe}_{3} \mathrm{O}_{4} @ \mathrm{PAA} / \mathrm{SBA} 15$ was performed to determine the kinetic parameters and half-life of each compound. The study of the kinetic parameters will allow identification of the degradation mechanism and comparison with other works and technologies in the field. For this study, $300 \mathrm{mg} \mathrm{L}^{-1}$ of hydrogen peroxide and $750 \mathrm{mg} \mathrm{L}^{-1}$ of MNP were used under acidic conditions ( $\mathrm{pH}$ 3.0). The experiments were carried out for $6 \mathrm{~h}$ by measuring the concentration at regular intervals, and the data were fitted to a pseudo-first order kinetic model (Figure 7). The $\mathrm{R}^{2}$ obtained reached values above 0.97 showing adequate correlation between the experimental data and the model equation. An increasing value of the kinetic constant was observed when the initial concentrations of estrogens were reduced, reaching a E1 half-life of $15 \mathrm{~min}$ for an initial concentration of $100 \mu \mathrm{g} \mathrm{L}{ }^{-1}$.

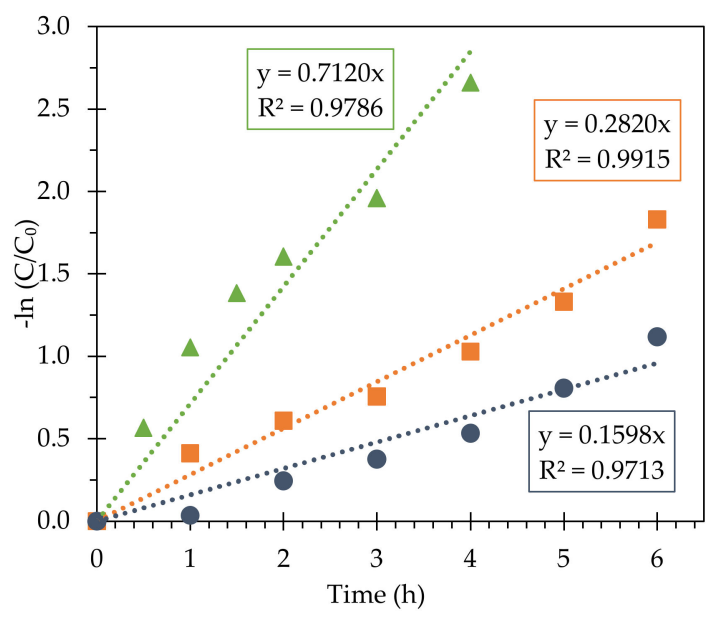

(a)

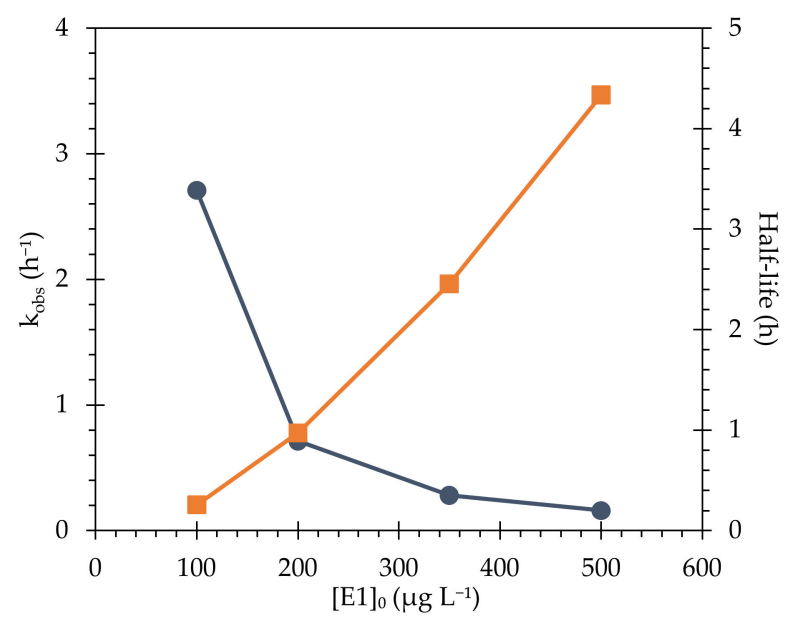

(b)

Figure 7. Pseudo-first order fit for E1 removal for (a) initial concentrations of 200 (blue circles), 350 (orange squares) and $500 \mu \mathrm{g} \mathrm{L}^{-1}$ (green triangles) and (b) kinetic constants (blue circles) and half-life (orange squares) obtained for the degradation experiments conducted at Fe concentrations of $750 \mathrm{mg} \mathrm{L}^{-1}$ and $\mathrm{H}_{2} \mathrm{O}_{2}$ at $300 \mathrm{mg} \mathrm{L}^{-1}$, at $\mathrm{pH} 3$.

The performance of MNPs versus E2 and EE2 removal considering different initial concentrations are compiled in Table 2 and depicted in Figures S11 and S12 of the Supplementary Information. The results for E2 and EE2 showed a similar trend to that obtained for the degradation of E1, for both the kinetic constants and half-life of the compounds. The highest kinetic value was obtained for the removal of EE2, starting from a concentration of $100 \mu \mathrm{g} \mathrm{L}^{-1}$, being three times lower when the initial target concentration is increased to $200 \mu \mathrm{g} \mathrm{L}^{-1}$. The experimental data fit well by applying a pseudo-first-order model, obtaining correlation coefficients higher than 0.97 for all cases. 
Table 2. Kinetic constants and half-life for $\mathrm{Fe}_{3} \mathrm{O}_{4} @ \mathrm{PAA} / \mathrm{SBA} 15$ degradation experiments performed in this study compared with other Fe-based nanocatalysts reported in the literature.

\begin{tabular}{|c|c|c|c|c|c|c|}
\hline Ref. & Pollutant & MNP & $\begin{array}{l}\text { Concentration } \\
\left(\mu \mathrm{g} \mathrm{L}^{-1}\right)\end{array}$ & $\begin{array}{l}\mathbf{k}_{\mathrm{obs}} \\
\left(\mathrm{h}^{-1}\right)\end{array}$ & $\begin{array}{l}t_{1 / 2} \\
(h)\end{array}$ & $\mathbf{R}^{2}$ \\
\hline \multirow{4}{*}{ This work } & \multirow{4}{*}{ E1 } & \multirow{4}{*}{$\mathrm{Fe}_{3} \mathrm{O}_{4} @ \mathrm{PAA} / \mathrm{SBA} 15$} & 500 & $0.160 \pm 0.011$ & $4.34 \pm 0.30$ & 0.9713 \\
\hline & & & 350 & $0.282 \pm 0.011$ & $2.46 \pm 0.09$ & 0.9915 \\
\hline & & & 200 & $0.712 \pm 0.043$ & $0.97 \pm 0.06$ & 0.9791 \\
\hline & & & 100 & $2.708 \pm 0.241$ & $0.26 \pm 0.02$ & 0.9769 \\
\hline \multirow{4}{*}{ This work } & \multirow{4}{*}{ E2 } & \multirow{4}{*}{$\mathrm{Fe}_{3} \mathrm{O}_{4} @ \mathrm{PAA} / \mathrm{SBA} 15$} & 500 & $0.228 \pm 0.016$ & $3.03 \pm 0.21$ & 0.9729 \\
\hline & & & 350 & $0.366 \pm 0.012$ & $1.89 \pm 0.06$ & 0.9931 \\
\hline & & & 200 & $0.898 \pm 0.060$ & $0.77 \pm 0.05$ & 0.9741 \\
\hline & & & 100 & $2.613 \pm 0.037$ & $0.27 \pm 0.00$ & 0.9717 \\
\hline \multirow{4}{*}{ This work } & \multirow{4}{*}{ EE2 } & \multirow{4}{*}{$\mathrm{Fe}_{3} \mathrm{O}_{4} @ \mathrm{PAA} / \mathrm{SBA} 15$} & 500 & $0.214 \pm 0.011$ & $3.24 \pm 0.17$ & 0.9840 \\
\hline & & & 350 & $0.361 \pm 0.015$ & $1.92 \pm 0.08$ & 0.9895 \\
\hline & & & 200 & $0.909 \pm 0.054$ & $0.76 \pm 0.04$ & 0.9796 \\
\hline & & & 100 & $3.211 \pm 0.271$ & $0.22 \pm 0.02$ & 0.9791 \\
\hline \multirow{3}{*}{ [45] } & \multirow{3}{*}{ BPA } & \multirow{3}{*}{ GS-Fe } & 25 & 1.338 & - & 0.9994 \\
\hline & & & 50 & 1.050 & - & 0.9972 \\
\hline & & & 75 & 0.468 & - & 0.9985 \\
\hline$[46]$ & TC & $\mathrm{CuFeO}_{2} /$ biochar & 20 & 0.272 & - & - \\
\hline$[47]$ & $\mathrm{BPA}$ & $\mathrm{Fe}_{3} \mathrm{O}_{4} @ \mathrm{MWCNT}$ & 70 & 0.330 & - & - \\
\hline [48] & MT & $\mathrm{Fe}_{3} \mathrm{O}_{4} @ \mathrm{MWCNT}$ & 212 & 0.396 & - & 0.9420 \\
\hline
\end{tabular}

BPA: Bisphenol-A, GS: grape seed extract (green phenol capping), TC: tetracycline, MWCNT: multi-walled carbon nanotubes, MT: $17 \alpha$-methyltestosterone.

As far as the authors are aware, there are not any published results of estrogen degradation by heterogenous Fenton that include the calculation of kinetic constants. Considering other published research works, estrogen removal showed similar kinetic constants compared to other types of micropollutants using coated and supported Fe-based nanoparticles. As an example, Guo et al. [45] reported similar values of a kinetic constant $\left(1.932 \mathrm{~h}^{-1}\right)$ studying the degradation of Bisphenol A at $\mathrm{pH} 3$, and using a green-synthesized nanoparticles with a concentration of $300 \mathrm{mg} \mathrm{L}^{-1}$. Xin et al. [46] obtained a kinetic constant of $0.2718 \mathrm{~h}^{-1}$ using $\mathrm{CuFeO}_{2} /$ biochar as a catalyst, studying the removal of tetracycline at pH 5 considering an optimum concentration of catalyst of $200 \mathrm{mg} \mathrm{L}^{-1}$. The use of carbon nanotubes as support for magnetite also delivered degradation constants in the same order of magnitude for Bisphenol A and methyltestosterone using similar reaction conditions [47,48]. After comparative analysis of kinetic constants, catalyst concentrations and reaction rates, no major differences are observed; however, $\mathrm{Fe}_{3} \mathrm{O}_{4} @ \mathrm{PAA} / \mathrm{SBA} 15 \mathrm{MNPs}$ present, as a unique feature, their excellent recovery and reuse potential. Extending the focus of comparative analysis to other heterogeneous catalytic processes such as photocatalysis using semiconductors (e.g., $\mathrm{TiO}_{2}, \mathrm{ZnO}$ ), the reported kinetic values are similar for estrogen removal. Oliveira et al. [49] reported a pseudo-first order rate constant of $0.240 \mathrm{~h}^{-1}$ for EE2 removal, which improved to $0.318 \mathrm{~h}^{-1}$ when an electro-assisted method was applied. $\mathrm{Xu}$ et al. [50] achieved higher reaction rates using magnetically functionalized titanium dioxide for E1 removal under UVC irradiation, obtaining a kinetic constant of $5.1 \mathrm{~h}^{-1}$.

\section{Conclusions}

Despite the proven efficacy of heterogeneous Fenton process for micropollutant abatement using nanostructured catalysts, the drawbacks associated with the discharge of iron in the treated effluent imply the need for approaches that allow the retention of the catalyst and its reuse in successive cycles. In this work, the influence of different coatings (PAA, $\mathrm{PEI}$ and $\mathrm{SiO}_{2}$ ) was evaluated based on their dye removal capacity. Besides its dye removal ability, PAA-coated magnetite showed an improved stability and catalyst recovery in subsequent cycles compared to bare magnetite nanoparticles. Based on these results, the in- 
clusion of a support is also studied, demonstrating that magnetite nanoparticles coated with polyacrylic acid and immobilized on mesoporous silica matrix support (SBA15) improved the efficiency of heterogeneous Fenton reactions, in terms of removal of dyes and endocrine disrupting compounds, achieving removal efficiencies above $90 \%$ using the optimized reaction conditions. The ease of recovery of the mesoporous matrix-supported nanoparticles due to their superparamagnetic properties is noteworthy, increasing their suitability for use in sequential batch cycles and thus reducing the operating costs associated with the loss of the catalyst, showing decay values in removal percentages below $5 \%$ and recoverability values up to $84 \%$. The results support the use of magnetite-based magnetic nanocatalysts as a cost-effective alternative to conventional Fenton processes in wastewater treatment for estrogen removal, providing kinetic values in the range of 2.6-3.2 $\mathrm{h}^{-1}$ considering the best conditions, similar to other heterogeneous advanced oxidation processes.

Supplementary Materials: The following are available online at https:/ / www.mdpi.com/article/10 $.3390 /$ nano11112902/s1, Figure S1: Scheme of the synthetic route for the preparation of $\mathrm{Fe}_{3} \mathrm{O}_{4} @ \mathrm{PAA} /$ SBA15, Figure S2: (a) Optimization of $\mathrm{H}_{2} \mathrm{O}_{2}$ concentration using $200 \mathrm{mg} \mathrm{L}^{-1}$ of bare $\mathrm{Fe}_{3} \mathrm{O}_{4}$ nanoparticles for the degradation of RB19 with an initial concentration of $30 \mathrm{mg} \mathrm{L}^{-1}$ and (b) kinetic fitting. The experimental data correspond to 100 (blue triangles), 200 (orange circles) and 500 (grey squares) $\mathrm{mg} \mathrm{L}^{-1}$ of $\mathrm{H}_{2} \mathrm{O}_{2}$, Figure S3: (a) Optimization of catalyst concentration (bare $\mathrm{Fe}_{3} \mathrm{O}_{4}$ ) using $100 \mathrm{mg} \mathrm{L}^{-1}$ of $\mathrm{H}_{2} \mathrm{O}_{2}$ for the degradation of RB19 with an initial concentration of $30 \mathrm{mg} \mathrm{L}^{-1}$ and (b) kinetic fitting. The experimental data correspond to 100 (blue triangles), 200 (orange circles), 500 (grey squares) and 750 (green diamonds) $\mathrm{mg} \mathrm{L}^{-1}$ of catalyst, Figure S4: (a) TEM images of $\mathrm{Fe}_{3} \mathrm{O}_{4}$, (b) $\mathrm{Fe}_{3} \mathrm{O}_{4} @ P E I,(c) \mathrm{Fe}_{3} \mathrm{O}_{4} @ P A A$ and (d) $\mathrm{Fe}_{3} \mathrm{O}_{4} @ \mathrm{SiO}_{2}$. Scale bars correspond to $50 \mathrm{~nm}$, Figure S5: Adsorption isotherm and pore-size distribution of $\mathrm{Fe}_{3} \mathrm{O}_{4} @ \mathrm{PAA} / \mathrm{SBA} 15$ nanocomposite, Figure S6: X-ray diffraction (XRD) characterization of magnetite-based nanoparticles, Figure S7: (a) X-ray diffraction (XRD) characterization and (b) low angle patterns of supported $\mathrm{Fe}_{3} \mathrm{O}_{4} @ \mathrm{PAA} / \mathrm{SBA} 15$ nanocomposite, Figure S8: Attenuated Total Reflectance (ATR) spectrum of $\mathrm{Fe}_{3} \mathrm{O}_{4} @ \mathrm{PAA} / \mathrm{SBA} 15$ nanocomposite, Figure S9: Thermogravimetric analysis (TGA) of $\mathrm{Fe}_{3} \mathrm{O}_{4} @ \mathrm{PAA} / \mathrm{SBA} 15$ nanocomposite, Figure S10: Vibrating sample magnetometer (VSM) curves of bare and coated $\mathrm{Fe}_{3} \mathrm{O}_{4} \mathrm{MNPs}$ and $\mathrm{Fe}_{3} \mathrm{O}_{4} @ \mathrm{PAA} / \mathrm{SBA} 15$ nanocomposite. The magnetization for coated silica and mesoporous silica nanocomposites was increased by a factor of 10 to improve the visualization of results. Insert figure shows a detail at low applied magnetic fields, confirming the superparamagnetic behavior at room temperature, Figure S11: Pseudo-first order fit for E2 removal for initial concentrations of 200 (blue circles), 350 (orange squares) and $500 \mathrm{\mu g} \mathrm{L}^{-1}$ (green triangles) obtained for the degradation experiments conducted at Fe concentrations of $750 \mathrm{mg} \mathrm{L}^{-1}$ and $\mathrm{H}_{2} \mathrm{O}_{2}$ at $300 \mathrm{mg} \mathrm{L}^{-1}$, at $\mathrm{pH}$ 3, Figure S12: Pseudo-first order fit for EE2 removal for initial concentrations of 200 (blue circles), 350 (orange squares) and $500 \mu \mathrm{g} \mathrm{L}^{-1}$ (green triangles) obtained for the degradation experiments conducted at Fe concentrations of $750 \mathrm{mg} \mathrm{L}^{-1}$ and $\mathrm{H}_{2} \mathrm{O}_{2}$ at $300 \mathrm{mg} \mathrm{L}^{-1}$, at $\mathrm{pH} 3$.

Author Contributions: Investigation, M.G.; writing—original draft preparation, J.G.-R. and J.J.C.; writing-reviewing and editing, J.G.-R., J.J.C., C.V.-V. and M.T.M.; resources, Z.V.-O. and Y.P.; conceptualization, C.V.-V., J.R., G.F. and M.T.M.; supervision, C.V.-V. and M.T.M. All authors have read and agreed to the published version of the manuscript.

Funding: This research was funded by HP-NANOBIO Project (PID2019-111163RB-I00) and MAGDEMON Project (PID2020-112626RB) granted by Spanish Ministry of Science and Innovation.

Acknowledgments: J.G.-R. thanks Xunta de Galicia Counseling of Education, Universities and Vocational Training (ED481A-2019/172) and Spanish Ministries of Science and Innovation and Universities (FPU19/00461) for his predoctoral fellowships. J.J.C. was supported by a postdoctoral fellowship from Xunta de Galicia (ED481B-2021/015). The authors belong to the Galician Competitive Research Groups (GRC) ED431C 2021/16 and ED432C 2021/37, co-funded by FEDER (UE). Authors would like to thank the use of RIAIDT-USC analytical facilities.

Conflicts of Interest: The authors declare no conflict of interest. 


\section{References}

1. De Souza Celente, G.; Colares, G.S.; da Silva Araújo, P.; Machado, Ê.L.; Lobo, E.A. Acute ecotoxicity and genotoxicity assessment of two wastewater treatment units. Environ. Sci. Pollut. Res. 2020, 27, 10520-10527. [CrossRef]

2. Pal, A.; Gin, K.Y.H.; Lin, A.Y.C.; Reinhard, M. Impacts of emerging organic contaminants on freshwater resources: Review of recent occurrences, sources, fate and effects. Sci. Total Environ. 2010, 408, 6062-6069. [CrossRef] [PubMed]

3. Crisp, T.M.; Clegg, E.D.; Cooper, R.L.; Wood, W.P.R.; Anderson, D.G.; Baetcke, K.P.R.; Hoffmann, J.L.; Morrow, M.S.; Rodier, D.J.; Schaeffer, J.E.; et al. Environmental endocrine disruption: An effects assessment and analysis. Environ. Health Perspect. 1998, 106, 11-56. [CrossRef] [PubMed]

4. Yoon, Y.; Ryu, J.; Oh, J.; Choi, B.-G.; Snyder, S.A. Occurrence of endocrine disrupting compounds, pharmaceuticals, and personal care products in the Han River (Seoul, South Korea). Sci. Total Environ. 2010, 408, 636-643. [CrossRef]

5. Giannakis, S.; Gamarra Vives, F.A.; Grandjean, D.; Magnet, A.; De Alencastro, L.F.; Pulgarin, C. Effect of advanced oxidation processes on the micropollutants and the effluent organic matter contained in municipal wastewater previously treated by three different secondary methods. Water Res. 2015, 84, 295-306. [CrossRef] [PubMed]

6. Paucar, N.E.; Kim, I.; Tanaka, H.; Sato, C. Ozone treatment process for the removal of pharmaceuticals and personal care products in wastewater. Ozone Sci. Eng. 2019, 41, 3-16. [CrossRef]

7. Teixeira, S.; Gurke, R.; Eckert, H.; Kühn, K.; Fauler, J.; Cuniberti, G. Photocatalytic degradation of pharmaceuticals present in conventional treated wastewater by nanoparticle suspensions. J. Environ. Chem. Eng. 2016, 4, 287-292. [CrossRef]

8. Mirzaei, A.; Chen, Z.; Haghighat, F.; Yerushalmi, L. Removal of pharmaceuticals from water by homo/heterogonous Fenton-type processes-A review. Chemosphere 2017, 174, 665-688. [CrossRef]

9. Deng, Y.; Zhao, R. Advanced Oxidation Processes (AOPs) in Wastewater Treatment. Curr. Pollut. Rep. 2015, 1, 167-176. [CrossRef]

10. Wang, N.; Zheng, T.; Zhang, G.; Wang, P. A review on Fenton-like processes for organic wastewater treatment. J. Environ. Chem. Eng. 2016, 4, 762-787. [CrossRef]

11. Rodriguez-Narvaez, O.M.; Peralta-Hernandez, J.M.; Goonetilleke, A.; Bandala, E.R. Treatment technologies for emerging contaminants in water: A review. Chem. Eng. J. 2017, 323, 361-380. [CrossRef]

12. Velichkova, F.; Julcour-Lebigue, C.; Koumanova, B.; Delmas, H. Heterogeneous Fenton oxidation of paracetamol using iron oxide (nano) particles. J. Environ. Chem. Eng. 2013, 1, 1214-1222. [CrossRef]

13. Abu-Dief, A.M.; Nassar, I.F.; Elsayed, W.H. Magnetic $\mathrm{NiFe}_{2} \mathrm{O}_{4}$ nanoparticles: Efficient, heterogeneous and reusable catalyst for synthesis of acetylferrocene chalcones and their anti-tumour activity. Appl. Organomet. Chem. 2016, 30, 917-923. [CrossRef]

14. El-Remaily, M.A.; Abu-Dief, A.M. $\mathrm{CuFe}_{2} \mathrm{O}_{4}$ nanoparticles: An efficient heterogeneous magnetically separable catalyst for synthesis of some novel propynyl-1H-imidazoles derivatives. Tetrahedron 2015, 71, 2579-2584. [CrossRef]

15. Mehdaoui, R.; El Ghali, A.; Cheikhrouhou, W.; Beyou, E.; Baouab, M.H.V. $\mathrm{Fe}_{3} \mathrm{O}_{4}$ nanoparticles coated by new functionalized tetraaza-2,3 dialdehyde micro-crystalline cellulose: Synthesis, characterization, and catalytic application for degradation of Acid Yellow 17. Iran. Polym. J. (Engl. Ed.) 2017, 26, 597-613. [CrossRef]

16. Laurent, S.; Forge, D.; Port, M.; Roch, A.; Robic, C.; Vander Elst, L.; Muller, R.N. Magnetic Iron Oxide Nanoparticles: Synthesis, Stabilization, Vectorization, Physicochemical Characterizations, and Biological Applications. Chem. Rev. 2010, 110, 2574. [CrossRef]

17. Leonel, A.G.; Mansur, A.A.P.; Mansur, H.S. Advanced Functional Nanostructures based on Magnetic Iron Oxide Nanomaterials for Water Remediation: A Review. Water Res. 2021, 190, 116693. [CrossRef] [PubMed]

18. Zubir, N.A.; Yacou, C.; Motuzas, J.; Zhang, X.; Diniz da Costa, J.C. Structural and functional investigation of graphene oxideFe3O4 nanocomposites for the heterogeneous Fenton-like reaction. Sci. Rep. 2015, 4, 4594. [CrossRef]

19. Wang, G.; Xiang, J.; Lin, J.; Xiang, L.; Chen, S.; Yan, B.; Fan, H.; Zhang, S.; Shi, X. Sustainable Advanced Fenton-like Catalysts Based on Mussel-Inspired Magnetic Cellulose Nanocomposites to Effectively Remove Organic Dyes and Antibiotics. ACS Appl. Mater. Interfaces 2020, 12, 51952-51959. [CrossRef]

20. Lin, J.; Chen, S.; Xiao, H.; Zhang, J.; Lan, J.; Yan, B.; Zeng, H. Ultra-efficient and stable heterogeneous iron-based Fenton nanocatalysts for degrading organic dyes at neutral $\mathrm{pH}$ via a chelating effect under nanoconfinement. Chem. Commun. 2020, 56, 6571-6574. [CrossRef]

21. González-Rodríguez, J.; Fernández, L.; Vargas-Osorio, Z.; Vázquez-Vázquez, C.; Piñeiro, Y.; Rivas, J.; Feijoo, G.; Moreira, M.T. Reusable $\mathrm{Fe}_{3} \mathrm{O}_{4} / \mathrm{SBA} 15$ Nanocomposite as an Efficient Photo-Fenton Catalyst for the Removal of Sulfamethoxazole and Orange II. Nanomaterials 2021, 11, 533. [CrossRef]

22. Atashin, H.; Malakooti, R. Magnetic iron oxide nanoparticles embedded in SBA-15 silica wall as a green and recoverable catalyst for the oxidation of alcohols and sulfides. J. Saudi Chem. Soc. 2017, 21, S17-S24. [CrossRef]

23. Massart, R. Preparation of aqueous magnetic liquids in alkaline and acidic media. IEEE Trans. Magn. 1981, 17, 1247-1248. [CrossRef]

24. Davila-Ibanez, A.B.; Salgueirino, V.; Martinez-Zorzano, V.; Mariño-Fernández, R.; García-Lorenzo, A.; Maceira-Campos, M.; Muñoz-Ubeda, M.; Junquera, E.; Aicart, E.; Rivas, J.; et al. Magnetic Silica Nanoparticle Cellular Uptake and Cytotoxicity Regulated by Electrostatic Polyelectrolytes-DNA Loading at Their Surface. ACS Nano 2012, 6, 747-759. [CrossRef]

25. Colilla, M.; Balas, F.; Manzano, M.; Vallet-Regí, M. Novel method to enlarge the surface area of SBA-15. Chem. Mater. 2007, 19, 3099-3101. [CrossRef]

26. Actor, Q.A. Advances in Nanotechnology Research and Application; ScholaryEditions: Atlanta, GA, USA, $2012 ;$ ISBN 9781464990472. 
27. Osorio, Z.V.; Pineiro, Y.; Vazquez, C.; Abreu, C.R.; Perez, M.A.A.; Quintela, M.A.L.; Rivas, J. Magnetic nanocomposites based on mesoporous silica for biomedical applications. Int. J. Nanotechnol. 2016, 13, 648. [CrossRef]

28. Couto, D.; Freitas, M.; Vilas-Boas, V.; Dias, I.; Porto, G.; Lopez-Quintela, M.A.; Rivas, J.; Freitas, P.; Carvalho, F.; Fernandes, E. Interaction of polyacrylic acid coated and non-coated iron oxide nanoparticles with human neutrophils. Toxicol. Lett. 2014, 225, 57-65. [CrossRef] [PubMed]

29. Schneider, C.A.; Rasband, W.S.; Eliceiri, K.W. NIH Image to ImageJ: 25 years of image analysis. Nat. Methods 2012, 9, 671-675.

30. Moldes-Diz, Y.; Gamallo, M.; Eibes, G.; Vargas-Osorio, Z.; Vazquez-Vazquez, C.; Feijoo, G.; Lema, J.M.; Moreira, M.T. Development of a Superparamagnetic Laccase Nanobiocatalyst for the Enzymatic Biotransformation of Xenobiotics. J. Environ. Eng. 2018, 144, 04018007. [CrossRef]

31. Fernández, L.; González-Rodríguez, J.; Gamallo, M.; Vargas-Osorio, Z.; Vázquez-Vázquez, C.; Piñeiro, Y.; Rivas, J.; Feijoo, G.; Moreira, M.T. Iron oxide-mediated photo-Fenton catalysis in the inactivation of enteric bacteria present in wastewater effluents at neutral pH. Environ. Pollut. 2020, 266, 115181. [CrossRef]

32. Wang, J.; Shao, X.; Zhang, Q.; Ma, J.; Ge, H. Preparation and photocatalytic application of magnetic $\mathrm{Fe}_{2} \mathrm{O}_{3} / \mathrm{SBA}-15$ nanomaterials. J. Mol. Liq. 2018, 260, 304-312. [CrossRef]

33. Nahar, Y.; Rahman, M.A.; Hossain, M.K.; Sharafat, M.K.; Karim, M.R.; Elaissari, A.; Ochiai, B.; Ahmad, H.; Rahman, M.M. A facile one-pot synthesis of poly(acrylic acid)-functionalized magnetic iron oxide nanoparticles for suppressing reactive oxygen species generation and adsorption of biocatalyst. Mater. Res. Express 2020, 7, 016102. [CrossRef]

34. Deng, S.; Zhang, X.; Lv, G.; Zhai, Y.; Yang, Z.; Zhu, Y.; Li, H.; Wang, F. Influence of zeolite carriers on the dyes degradation for framework Fe-doped zeolite catalysts. J. Sol-Gel Sci. Technol. 2019, 91, 54-62. [CrossRef]

35. Aliyan, H.; Fazaeli, R.; Jalilian, $\mathrm{R}_{\text {. }} \mathrm{Fe}_{3} \mathrm{O}_{4} @$ mesoporous SBA-15: A magnetically recoverable catalyst for photodegradation of malachite green. Appl. Surf. Sci. 2013, 276, 147-153. [CrossRef]

36. Zhang, J.; Zhuang, J.; Gao, L.; Zhang, Y.; Gu, N.; Feng, J.; Yang, D.; Zhu, J.; Yan, X. Decomposing phenol by the hidden talent of ferromagnetic nanoparticles. Chemosphere 2008, 73, 1524-1528. [CrossRef]

37. Yang, J.; Zhang, Y.; Zeng, D.; Zhang, B.; Hassan, M.; Li, P.; Qi, C.; He, Y. Enhanced catalytic activation of photo-Fenton process by $\mathrm{Cu}_{0} \cdot 5 \mathrm{Mn}_{0} \cdot 5 \mathrm{Fe}_{2} \mathrm{O}_{4}$ for effective removal of organic contaminants. Chemosphere 2020, 247, 125780. [CrossRef]

38. Yoon, J.; Lee, Y.; Kim, S. Investigation of the reaction pathway of $\mathrm{OH}$ radicals produced by Fenton oxidation in the conditions of wastewater treatment. Water Sci. Technol. 2001, 44, 15-21. [CrossRef] [PubMed]

39. Zhou, Y.; Shen, J.; Bai, Y.; Li, T.; Xue, G. Enhanced degradation of Acid Red 73 by using cellulose-based hydrogel coated Fe ${ }_{3} \mathrm{O}_{4}$ nanocomposite as a Fenton-like catalyst. Int. J. Biol. Macromol. 2020, 152, 242-249. [CrossRef]

40. Pukdee-Asa, M.; Su, C.C.; Ratanatamskul, C.; Lu, M.C. Degradation of azo dye by the fluidised-bed Fenton process. Color. Technol. 2012, 128, 28-35. [CrossRef]

41. De Laat, J.; Gallard, H. Catalytic decomposition of hydrogen peroxide by Fe(III) in homogeneous aqueous solution: Mechanism and kinetic modeling. Environ. Sci. Technol. 1999, 33, 2726-2732. [CrossRef]

42. Ding, X.; Gutierrez, L.; Croue, J.P.; Li, M.; Wang, L.; Wang, Y. Hydroxyl and sulfate radical-based oxidation of RhB dye in $\mathrm{UV} / \mathrm{H}_{2} \mathrm{O}_{2}$ and $\mathrm{UV} /$ persulfate systems: Kinetics, mechanisms, and comparison. Chemosphere 2020, 253, 126655. [CrossRef]

43. Zhang, Y.; Zhou, M. A critical review of the application of chelating agents to enable Fenton and Fenton-like reactions at high pH values. J. Hazard. Mater. 2019, 362, 436-450. [CrossRef] [PubMed]

44. Lin, J.; Hu, Y.; Xiao, J.; Huang, Y.; Wang, M.; Yang, H.; Zou, J.; Yuan, B.; Ma, J. Enhanced diclofenac elimination in Fe(II)/peracetic acid process by promoting Fe(III)/Fe(II) cycle with ABTS as electron shuttle. Chem. Eng. J. 2021, 420, 129692. [CrossRef]

45. Guo, B.; Xu, T.; Zhang, L.; Li, S. A heterogeneous fenton-like system with green iron nanoparticles for the removal of bisphenol A: Performance, kinetics and transformation mechanism. J. Environ. Manag. 2020, 272, 111047. [CrossRef]

46. Xin, S.; Ma, B.; Liu, G.; Ma, X.; Zhang, C.; Ma, X.; Gao, M.; Xin, Y. Enhanced heterogeneous photo-Fenton-like degradation of tetracycline over $\mathrm{CuFeO}$ /biochar catalyst through accelerating electron transfer under visible light. J. Environ. Manag. 2021, 285, 112093. [CrossRef] [PubMed]

47. Cleveland, V.; Bingham, J.-P.; Kan, E. Heterogeneous Fenton degradation of bisphenol A by carbon nanotube-supported Fe $\mathrm{O}_{4}$. Sep. Purif. Technol. 2014, 133, 388-395. [CrossRef]

48. Hu, X.; Deng, Y.; Gao, Z.; Liu, B.; Sun, C. Transformation and reduction of androgenic activity of $17 \alpha$-methyltestosterone in $\mathrm{Fe}_{3} \mathrm{O}_{4} / \mathrm{MWCNTs}-\mathrm{H} 2 \mathrm{O} 2$ system. Appl. Catal. B Environ. 2012, 127, 167-174. [CrossRef]

49. Oliveira, H.G.; Ferreira, L.H.; Bertazzoli, R.; Longo, C. Remediation of 17- $\alpha$-ethinylestradiol aqueous solution by photocatalysis and electrochemically-assisted photocatalysis using $\mathrm{TiO}_{2}$ and $\mathrm{TiO}_{2} / \mathrm{WO} 3$ electrodes irradiated by a solar simulator. Water Res. 2015, 72, 305-314. [CrossRef]

50. $\mathrm{Xu}, \mathrm{S}$.; $\mathrm{Lu}, \mathrm{H}$.; Chen, L.; Wang, X. Molecularly imprinted $\mathrm{TiO}_{2}$ hybridized magnetic $\mathrm{Fe}_{3} \mathrm{O}_{4}$ nanoparticles for selective photocatalytic degradation and removal of estrone. RSC Adv. 2014, 4, 45266-45274. [CrossRef] 